\title{
Male Breast Cancer Prognostic Factors Versus Female Counterparts with Propensity Scores and Matched-Pair Analysis
}

Edward Yu ${ }^{1}$, Larry Stitt ${ }^{2}$, Olga Vujovic ${ }^{3}$, Kurian Joseph ${ }^{4}$, Avi Assouline ${ }^{5}$, Jawaid Younus ${ }^{6}$, Francisco Perera ${ }^{7}$, Patricia Tai ${ }^{8}$

1. Department of Oncology, Division of Radiation Oncology, Western University 2. Clinical Research Unit, London Health Sciences Centre 3. Department of Radiation Oncology, London Regional Cancer Program, Western University, London, Ontario, CA 4. Department of Oncology, Cross Cancer Institute, University of Alberta 5. Department of Radiation Oncology, Centre Clinique de la Porte de Saint-Cloud 6. Medical Oncology, Western University 7. Radiation Oncology, London Regional Cancer Program, Western University 8. Department of Radiation Oncology, Allan Blair Cancer Center, University of Saskatchewan

$\square$ Corresponding author: Edward Yu, eyu@uwo.ca

Disclosures can be found in Additional Information at the end of the article

\section{Abstract}

Objective: To assess the effect of prognostic factors and their impact on survival in male and female breast cancer.

Methods: Medical records for men and women diagnosed with breast cancer referred to the cancer center for treatment were reviewed. Patients with distant metastatic diseases were excluded. Data on prognostic factors including age, nodal status, resection margin, use of hormonal therapy, chemotherapy with and without hormone and radiation therapy (RT), survival, and recurrence were analyzed. Survival estimates were obtained using Kaplan-Meier methodology. The Cox regression interaction was used to compare male and female differences in prognostic factors. Male breast cancer (MBC) and female breast cancer (FBC) were matched according to propensity scores and survival compared using Cox regression.

Results: From 1963-2006, there were 75 MBC and 1,313 FBC totaling 1,388 breast cancers. The median age of the cohort was 53 (range: 23-90) years. Median follow-up was 90 (range: 0.4339) months. Prognostic factors of patients were balanced among the groups after adjusting for propensity scores. A Cox model adjusting for propensity scores showed that overall survival $(\mathrm{OS})(\mathrm{HR}=2.52(1.65,3.86), \mathrm{P}<0.001)$ and distant disease recurrence-free survival (DDRFS) (HR= $2.39(0.75,3.04), \mathrm{P}=0.003)$ were significantly different for MBC and FBC. Analyses that stratified by propensity score quintiles had similar findings: OS HR=2.41 $(1.67,3.47)$, $\mathrm{P}<0.001)$; DDRFS HR=2.89 (1.81, 4.60), $\mathrm{P}<0.001)$. When $\mathrm{MBC}$ and FBC were matched $(1: 3)$ by propensity scores, differences between $\mathrm{MBC}$ and $\mathrm{FBC}$ were again observed in $\mathrm{OS}(\mathrm{HR}=1.94$, 95\%CI:1.18-3.19, $\mathrm{P}=0.009)$ and DDRFS (HR=2.79, 95\%CI:1.36-5.75, $\mathrm{P}=0.005)$ with $\mathrm{MBC}$ at a higher risk of death and disease recurrence compared to FBC .

Yu et al. This is an open access article distributed under the terms of the Creative Commons Attribution License CC-BY 3.0., which permits unrestricted use, distribution, and reproduction in any medium, provided the original author and source are credited.
Received 06/04/2015
Review began 06/09/2015 Review ended 09/18/2015 Published 10/16/2015
Conclusion: This large series showed that MBC and FBC survivals are not similar, with MBC having a worse outcome. The finding of this study needs confirmation from a complete prospective database. 
Categories: Radiation Oncology, Oncology

Keywords: male, female, breast cancer, prognostic factors, propensity scores, matched-paired, survival

\section{Introduction}

Male breast cancer (MBC) makes up fewer than 1\% of all cancer cases in men and fewer than 1\% of all breast cancer cases in the United States [1]. In 2014, 2,360 new cases were diagnosed in the United States and approximately 430 men died from this disease [2]. Because of its rarity, little is known about its etiology and there have been no randomized control trials of MBC. The management of MBC is primarily extrapolated from female breast cancer (FBC) trials and clinical data. Some investigators reported $\mathrm{MBC}$ has poor prognostic factors that may be responsible for survival outcome compared to FBC, others claimed equal prognosis for both sexes, and the controversy has not been completely resolved [3-10]. We have previously reported that prognostic factors influence survival differently in $\mathrm{MBC}$ and $\mathrm{FBC}$ [11]. The present study is to investigate the influence of prognostic factors when $\mathrm{MBC}$ and $\mathrm{FBC}$ are paired and matched in prognostic factors with propensity scores analysis.

\section{Materials And Methods}

Ethics approval was obtained through the Western University Health Sciences Research Ethics Board (approval \#100929). Adult male and female patients with the diagnosis of invasive mammary carcinoma of the breast who were referred to the London Regional Cancer Program (LRCP) over the past 40 years were reviewed.

The patients were staged using the Seventh American Joint Committee on Cancer (AJCC) criteria for breast cancer [12]. Patients with Stage VI $\left(\mathrm{M}_{1}\right)$ disease were excluded.

All patients received surgery consisting of either a lumpectomy and axillary dissection for breast preservation, a simple mastectomy and axillary dissection, or a modified radical mastectomy (MRM) for non-breast preservation management. Adjuvant radiation therapy was given in postoperative setting for high-risk patients with close/positive resection margins or tumor with positive nodes [13]. Radiation dose ranged from $40 \mathrm{~Gy}$ in 15 fractions to $50 \mathrm{~Gy}$ in 25 fractions to the breast or chest wall with or without supraclavicular axillary and internal mammary regions. A boost dose of $10 \mathrm{~Gy}$ in 5 fractions with electrons was generally given to patients with margin involvement. The radiation treatment energy was cobalt-60 or a 4-MV linear accelerator. Radiation treatment was given after the completion of chemotherapy.

Chemotherapy and tamoxifen were given in the adjuvant setting for high-risk patients with nodal involvement. The chemotherapy comprised of CMF (cyclophosphamide, methotrexate, and 5-fluorouracil), or CEF (cyclophosphamide, epirubicin, and 5-fluorouracil). Tamoxifen was also offered for estrogen receptor (ER) positive patients.

The primary endpoints for our review were overall survival (OS) and cancer-specific survival (CSS). The secondary endpoints were disease-free survival (DFS) and distant failure. Survival estimates were obtained using Kaplan-Meier methodology. Cox regression was used to compare male and female differences in prognostic factors. Male and female breast cancers were matched according to the propensity scores and survival compared using Cox regression.

To control for differences in the baseline characteristics, a propensity score was calculated for each male and female patient using a logistic regression model [14]. The model included patient cancer-related characteristics, such as age at diagnosis, tumor size, nodes removed, node positivity, resection margin status, hormonal treatment, chemotherapy treatment, and radiation treatment. We have incorporated changes in surgical technique by incorporating 


\section{Cureus}

years of surgery (before and after 1987) in our propensity scores. Once the model was fitted, regression analyses were used to evaluate whether the baseline covariates were balanced across the study groups after adjusting for propensity scores. Potential time trends for cancer treatment, including the year of surgery in breast cancer management, was adjusted.

Cox regression analysis was used to compare the survival of female and male breast cancer, adjusting for propensity scores in three ways. First, the propensity scores as a continuous covariate in a Cox model comparing survival was included. Secondly, patients were classified into quintiles based on their propensity for gender and fitted stratified Cox model. Finally, patients were matched male to female by their propensity scores and compared survival among study groups [15-18].

\section{Results}

From Jan 1963 to Dec 2006, a total of 1,388 breast cancer patient charts were reviewed. There were $75 \mathrm{MBC}$ and 1,313 FBC. They were treated at a similar period of time; MBC were from 1979-2006 and FBC were from 1963-1992.

The median age of the cohort was 63 years (23-90 years): the median age for males was 65 years (range: $35-83$ years) and for females was 60 years (range: $23-90$ years).

The median follow-up time was 90 months (ranged from 0.39-339 months).

Patient characteristics included age, tumor size, tumor grade, nodal status, resection margins, hormonal therapy, chemotherapy with or without hormonal therapy, and radiation therapy, which were previously reported (Table 1$)$ [11]. MBC patients were older in age $(\mathrm{P}=0.001)$ and their tumors were in the lower and intermediate grades $(\mathrm{P}=0.004)$. MBC tumor had a higher proportion ER positive ( $83 \%$ VS $57 \%$ ), often treated with hormonal therapy only ( $\mathrm{P}=0.001$ ), and less often received chemotherapy-based treatment compared to FBC $(\mathrm{P}=0.001)$. After adjusting for propensity scores, all covariates were well-balanced among the groups and no clinically relevant differences between males and females were seen.

\begin{tabular}{|c|c|c|}
\hline Characteristics & Male $(n=75)$ & Female $(n=1313)$ \\
\hline \multicolumn{3}{|l|}{ Age at Diagnosis } \\
\hline Mean (sd) & 64.1 (11.6) & $57.8(12.2)$ \\
\hline Missing & 0 & 0 \\
\hline \multicolumn{3}{|l|}{ Tumour Size (cm) } \\
\hline$\leq 2$ & $36 / 68$ (52.9\%) & 692/1254 (55.2\%) \\
\hline $2-5$ & 29/68 (42.7\%) & 489/1254 (39.0\%) \\
\hline$>5$ & 3/68 (4.4\%) & 73/1254 (5.8\%) \\
\hline Missing & 7/75 (9.3\%) & 59/1313 (4.6\%) \\
\hline
\end{tabular}

Nodes Removed

0.149

0.522

\section{P Value}

Unadjusted Adjusted $^{\bigvee}$ 


\section{Cureus}

$\leq 10$

Missing

Node positivity

Yes

No

Missing

Margin Status

Close/Positive ( $<2 \mathrm{~mm}$ )

Negative (>2 mm)

Missing

Hormone Treatment

Yes

No

Missing

Chemotherapy

Yes

No

Missing

Radiation Treatment

Yes

No

Missing

Year of Surgery

After 1987

At and before 1987
$35 / 72(49.6 \%) \quad 717(1252(67.3 \%)$

$3(4.0 \%)$

$61(4.7 \%)$

$38 / 75(50.7 \%)$

733/1313 (55.9\%)

0.379

0.227

$37 / 75(49.3 \%) \quad 580 / 1313(44.1 \%)$

$0(0.0 \%)$

$0(0.0 \%)$

0.011

0.988

$\begin{array}{ll}11 / 60(18.3 \%) & 106 / 1222(8.7 \%) \\ 49 / 60(81.7 \%) & 1116 / 1222(91.3 \%) \\ 15(20.0 \%) & 91(7.0 \%)\end{array}$

$<0.001$

0.501

$39 / 73(53.4 \%) \quad 220 / 1271(17.3 \%)$

$34 / 73(46.6 \%) \quad 1051 / 1271(82.7 \%)$

$2(2.7 \%)$

$42(3.3 \%)$

$<0.001$

0.315

$12 / 75(16.0 \%) \quad 597 / 1311(45.5 \%)$

63/75(84.0\%) $\quad 714 / 1311(54.5 \%)$

$0(0.0 \%)$

$2(0.2 \%)$

0.076

0.733

$46 / 75(61.3 \%) \quad 931 / 1312(71.0 \%)$

$24 / 75(38.7 \%) \quad 381 / 1312(29.0 \%)$

$0(0.0 \%)$

$1(0.2 \%)$

$62 / 75(82.7 \%)$

$623 / 1313(47.5 \%)$

$<0.001$

0.155

13/75(17.3\%)

\section{TABLE 1: Baseline Characteristics of Patients with Male Breast Cancer and Female}

Breast Cancer

$Y=$ Adjusted for patient propensity scores and with year of surgery.

sd $=$ standard derivation 


\section{Cureus}

The five-year and 10-year CSS and OS rates for node negative and positive patients are shown in Table 2.

$\begin{array}{lllc}\text { A Male Breast Cancer (MBC) and Female Breast Cancer (FBC) Cancer Specific Survival } \\ \text { CSS } & & 5 \text { years } & 10 \text { years } \\ \text { Negative nodes } & \text { MBC } & 94.5 \% & 53.8 \% \\ & \text { FBC } & 91.8 \% & 84.7 \% \\ \text { Positive nodes } & \text { MBC } & 79.4 \% & 55.4 \% \\ & \text { FBC } & 72.6 \% & 56.2 \%\end{array}$

B Male Breast Cancer (MBC) and Female Breast Cancer (FBC) Overall Survival (OS) with Time

OS

Negative nodes

Positive nodes

$\begin{array}{lll} & 5 \text { years } & 10 \text { years } \\ \text { MBC } & 68.7 \% & 39.0 \% \\ \text { FBC } & 90.2 \% & 85.3 \% \\ \text { MBC } & 74.6 \% & 33.7 \% \\ \text { FBC } & 68.3 \% & 49.2 \%\end{array}$

\section{TABLE 2: A. Male Breast Cancer (MBC) and Female Breast Cancer (FBC) Cancer- Specific Survival (CSS) with Time B. Male Breast Cancer (MBC) and Female Breast Cancer (FBC) Overall Survival (OS) with Time}

Prognostic factors, including age, tumor size, nodes removed, resection margin status, hormonal therapy, chemotherapy, and radiation treatment were used for propensity scores analysis in male and female breast cancer (Table 3). A Cox model adjusting for propensity scores indicated that $\mathrm{OS}(\mathrm{HR}=2.52(1.65,3.86), \mathrm{P}<0.001)$ and DDRFS $(\mathrm{HR}=2.39(0.75,3.04)$, $\mathrm{P}=0.003)$ was significantly different for MBC and FBC. Analyses stratified by propensity score quintiles had similar findings (OS HR = 2.41 (1.67, 3.47), $\mathrm{P}<0.001)$; DDRFS HR = $2.89(1.81,4.60)$, $\mathrm{P}<0.001)$. Finally, when MBC and FBC were matched (1:3) by propensity scores, differences between $\mathrm{MBC}$ and FBC were again observed in OS (HR = 1.94, 95\%CI:1.18-3.19, P=0.009) (Figure 1) and DDRFS (HR = 2.79, 95\%CI:1.36-5.75, P=0.005) (Figure 2). For the subset of patients for whom estrogen receptors and tumor grades that were available, analyses were done and there was no difference between male and female breast cancer when adjusting for propensity scores. Both estrogen receptors and tumor grades did not contribute significantly to the models when adjustment was made. Analyses adjusting for potential time trends in the use of breast cancer treatment including surgery were employed, and the association between the MBC and FBC and survival differences remained unchanged. 


\section{Cureus}

\begin{tabular}{|c|c|c|}
\hline & $\begin{array}{l}\text { HR }(95 \% \mathrm{CL}), \mathrm{P} \\
\text { value }\end{array}$ & $\begin{array}{l}\mathrm{HR}(95 \% \mathrm{CL}), \mathrm{P} \\
\text { value }\end{array}$ \\
\hline Entire cohort with adjusting for time trends and years of surgery & OS & DDRFS \\
\hline Adjusting for propensity scores & $\begin{array}{l}2.52(1.65,3.86) \\
P<0.001\end{array}$ & $\begin{array}{l}2.39(0.75,3.04) \\
P<0.003\end{array}$ \\
\hline Stratified by propensity score quintiles & $\begin{array}{l}2.41(1.67,3.46) \\
P<0.001\end{array}$ & $\begin{array}{l}2.89(1.81,4.60) \\
P<0.001\end{array}$ \\
\hline $\begin{array}{l}\text { Match-paired analysis(1:3) MBC:FBC Matched on propensity score with } \pm \\
0.05,28 \text { matched pair }\end{array}$ & $\begin{array}{l}1.94(1.18,3.19) \\
P=0.009\end{array}$ & $\begin{array}{l}2.79(1.36,5.75) \\
P=0.005\end{array}$ \\
\hline
\end{tabular}

\section{TABLE 3: Propensity Score Analysis Compared of Overall Survival (OS) and Distant}

Disease Recurrence Free Survival (DDRFS) in Male Breast Cancer and Female Breast

\section{Cancer}

The HR represents the risk of death of a patient being male breast cancer (MBC) compared with a patient being female breast cancer (FBC)

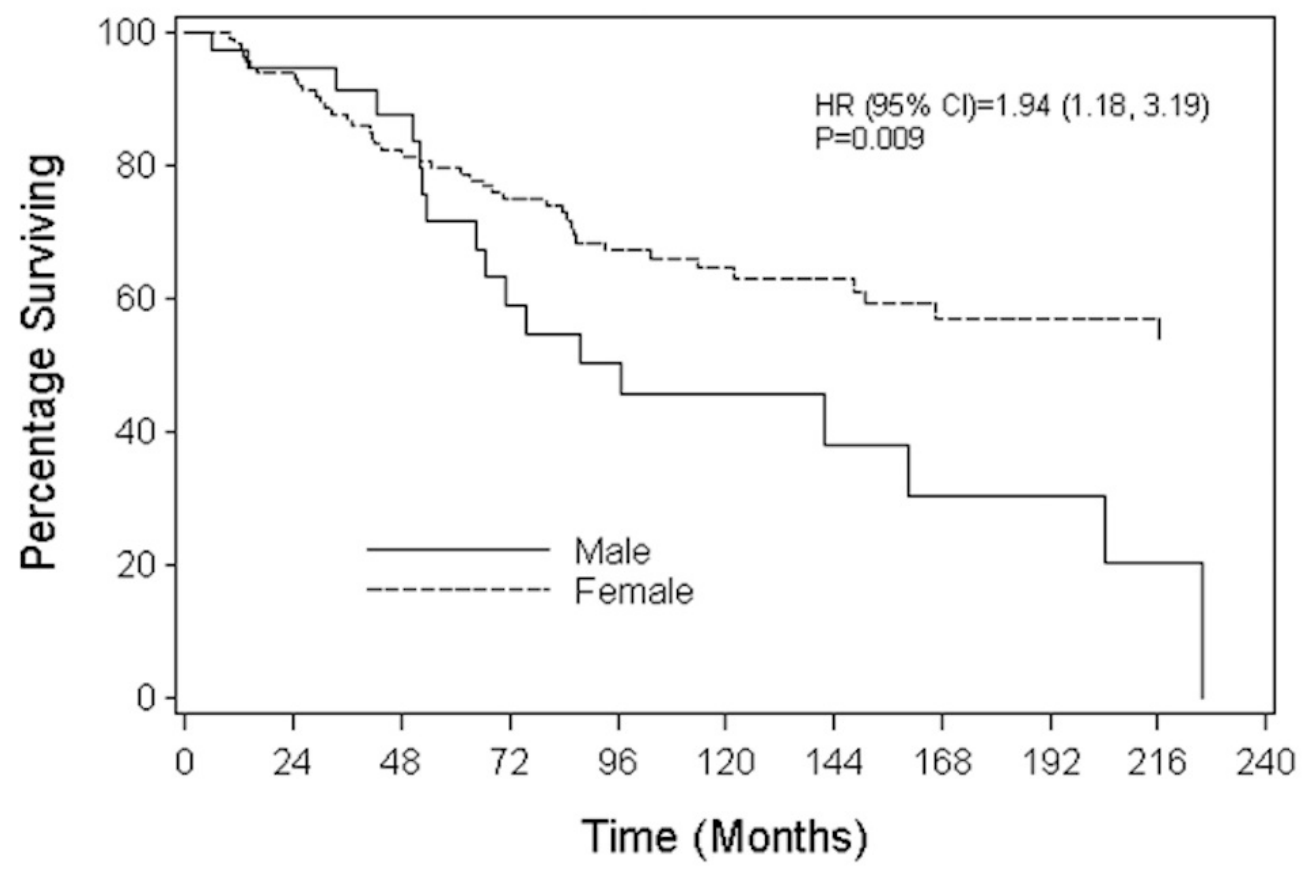

FIGURE 1: Overall Survival of Male Breast Cancer and Female Breast Cancer 


\section{Cureus}

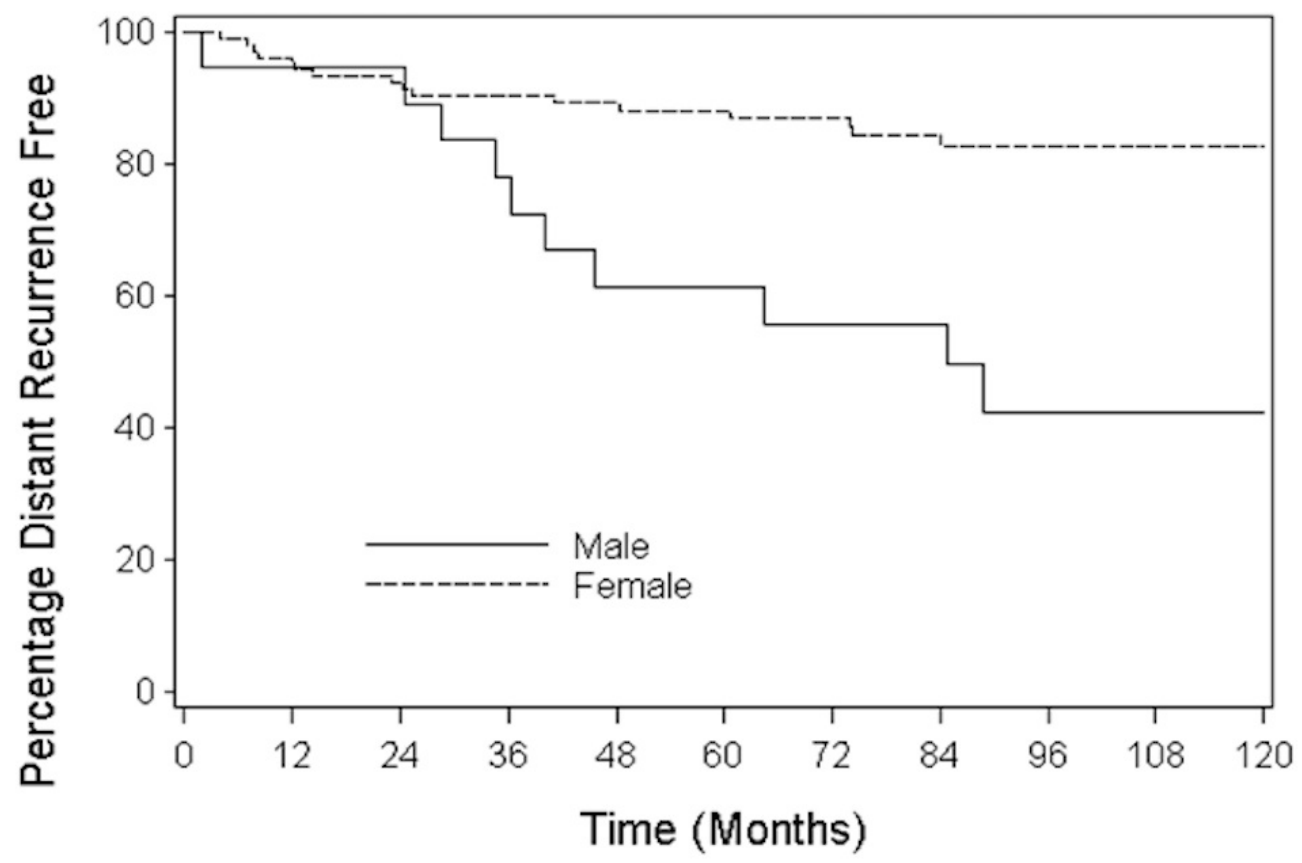

FIGURE 2: Distant Disease Recurrence-Free Survival of Male Breast Cancer and Female Breast Cancer

HR $(95 \% \mathrm{Cl}=2.79(1.36,5.75)$

$\mathrm{P}=0.005$

\section{Discussion}

Our data showed that MBC and FBC prognoses are not similar with the propensity scores analysis. MBC survivals are inferior compared to FBC. Different from FBC, but consistent with the literature, patients with MBC are older in age, tumor characteristics are more often with low to intermediate grades, and have a higher proportion of estrogen-positive receptors. In our center, they were often managed with tamoxifen rather than chemotherapy.

Although the prognostic differences between MBC and FBC are not entirely clear, potential under-treatment with systemic therapy and poor compliance to Tamoxifen in MBC have been reported [11, 19-20]. In our series, 50\% lymph node involvement in MBC only $16 \%$ received chemotherapy whereas over $45 \%$ of FBC received chemotherapy. Research in progress is ongoing to improve patient care, including the development of specific geriatric screening tools to implement more aggressive systemic therapy to assist in breast cancer management who are older in age and at high risk for disease recurrence [21]. Further research is being directed at targeting estrogen receptor therapy in $\mathrm{MBC}$, with preliminary data showing fulvestrant was an effective and safe treatment in hormone receptor-positive pretreated metastatic MBC [22].

Several limitations and strengths in our study are worth noting. Limitations include single center retrospective data that lacks patient co-morbidity information, limited ability to match all MBC with FBC for the specified criteria, and the patient cohort was not treated at the exact same period of time. However, we used propensity score methods to balance the study groups for covariates, including tumor size, nodal involvement, resection margin status, and cancer 
treatments, that are important prognostic factors for breast cancer patients receiving adjuvant therapy management. Although the controversy still remains, as others do not report a difference in $\mathrm{MBC}$ and FBC survival, our study is the first to match patient characteristics with propensity scores analysis and report that MBC differs from FBC in DDRFS and OS [23-25].

The International Consortium Study, which includes the International Male Breast Cancer Program, joint production of European Organization for Research and Treatment of Cancer, Translational Breast Cancer Research Consortium, the Breast Inter-Group, and the North American Breast Cancer Group, has collected data for a retrospective analysis of all male breast cancer diagnosed and treated in the last 20 years. There is data for over 1,000 patients with $\mathrm{M}_{0}$ (no distant metastatic) disease. Tumor blocks were collected for the analysis of tumor biological characteristics, pathological review of ER, progesterone receptors, and HER-2 and Ki 67 expressions. The results of this International Consortium Study will hopefully provide further insight on MBC natural history and future management [26].

\section{Conclusions}

This large series showed that MBC and FBC survivals are not similar. MBC differs from FBC in OS and in DDRFS significantly when matched by the propensity scores of their prognostic factors. Male patients with breast cancer are twice as likely to die of cancer than their female counterparts. The finding of this study needs confirmation from a complete prospective database.

\section{Appendices}

Presented in part at the 56th Annual American Society for Radiation Oncology meeting at SanFrancisco, CA, Sept 2014

\section{Additional Information}

\section{Disclosures}

Human subjects: Consent was obtained by all participants in this study. Western University Health Sciences Research Ethics Board issued approval 100929. Animal subjects: All authors have confirmed that this study did not involve animal subjects or tissue. Conflicts of interest: In compliance with the ICMJE uniform disclosure form, all authors declare the following: Payment/services info: All authors have declared that no financial support was received from any organization for the submitted work. Financial relationships: All authors have declared that they have no financial relationships at present or within the previous three years with any organizations that might have an interest in the submitted work. Other relationships: All authors have declared that there are no other relationships or activities that could appear to have influenced the submitted work.

\section{Acknowledgements}

The authors wish to thank Mary-Ellen Coughlin for her skillful preparation of this manuscript, Frances Whiston for data management, and Drs. Hiro Suzuki, Tarek Elfiki, Gary Yau, and Michael Lock for team support.

\section{References}

1. Jemal A, Siegel R, Ward E, Hao Y, Xu J, Murray T, Thun MJ: Cancer statistics, 2008. CA Cancer J Clin. 2008, 58:71-96. 10.3322/CA.2007.0010

2. Cancer Facts \& Figures 2015, American Cancer Society . (2015). Accessed: October 12, 2015: http://www.cancer.org/research/cancerfactsstatistics/cancerfactsfigures2015/index. 
3. Joshi MG, Lee AK, Loda M, Camus MG, Pedersen C, Heatley GJ, Hughes KS: Male breast carcinoma: an evaluation of prognostic factors contributing to a poorer outcome. Cancer. 1996, 77:490-98. 10.1002/(SICI)1097-0142(19960201)77:3<490::AID-CNCR10>3.0.CO;2-\#

4. Crichlow RW: Carcinoma of the male breast. Surg Gynecol Obstet. 1972, 134:1011-19.

5. Ramantanis G, Besbeas S, Garas JG: Breast cancer in the male: A report of 138 cases . World J Surg. 1980, 4:621-24. 10.1007/BF02401650

6. Ajayi DO, Osegbe DN, Ademiluyi SA: Carcinoma of the male breast in West Africans and a review of world literature. Cancer. 1982, 50:1664-67. 10.1002/1097-

0142(19821015)50:8<1664::AID-CNCR2820500834>3.0.CO;2-N

7. Erlichman C, Murphy KC, Elhakim T: Male breast cancer: A 13 year review of 89 patients . J Clin Oncol. 1984, 2:903-9.

8. Carlsson G, Hafström L, Jönsson PE: Male breast cancer. Clin Oncol. 1981, 7:149-155.

9. Ouriel K, Lotze MT, Hinshaw JR: Prognostic factors of carcinoma of the male breast . Surg Gynecol Obstet. 1984, 159:373-76.

10. Adami HO, Holmberg L, Malker B, Ries L: Long-term survival in 406 males with breast cancer . Br J Cancer. 1985, 52:99-103. 10.1038/bjc.1985.155

11. Yu E, Stitt L, Vujovic O, Joseph K, Assouline A, Au J, Younus J, Perera F, Tai P: Prognostic factors for male breast cancer: similarity to female counterparts. Anticancer Res. 2013, 33:2227-31.

12. Compton CC, Byrd DR, Garcia-Aguilar J, Kurtzman SH, Olawaiye A, Washington MK: Breast. AJCC Cancer Staging Atlas: A Companion to the Seventh Editions of the AJCC Cancer Staging Manual and Handbook, 2nd edition. Compton CC, Byrd DR, Garcia-Aguilar J, Kurtzman SH, Olawaiye A, Washington MK (ed): Springer, New York; 2012. 419-440. 10.1007/978-1-46142080-4_32

13. Yu E, Suzuki H, Younus J, Elfiki T, Stitt L, Yau G, Vujovic O, Perera F, Lock M, Tai P: The impact of post-mastectomy radiation therapy on male breast cancer patients--a case series. Int J Radiat Oncol Bio Phys. 2012, 82:696-700. 10.1016/j.ijrobp.2011.01.010

14. Rubin DB: Estimating casual effects from large data sets using propensity scores . Ann Intern Med. 1997, 127:757-63. 10.7326/0003-4819-127-8_Part_2-199710151-00064

15. Rosenbaum PR, Rubin DB: The central role of propensity score in observational studies for causal effects. Biometrika. 1983, 70:41-55. 10.1093/biomet/70.1.41

16. Rubin DB: Inference and missing data. Biometrika. 1976, 63:581-92. 10.1093/biomet/63.3.581

17. van Buuren S, Brand JPL, Groothuis-Oudshoorn CGM, Rubin DB: Fully conditional specification in multiple imputation. J Stat Comput Simul. 2006, 76:1049-64. 10.1080/10629360600810434

18. Wisnivesky JP, Halm EA, Bonomi M, Smith C, Mhango G, Bagiella E: Postoperative radiotherapy for elderly patients with stage III lung cancer. Cancer. 2012, 118:4478-85. 10.1002/cncr.26585

19. Naito Y, Mukai H, Nagai S: Elderly breast cancer therapy: A Japanese experience . Jpn J Clin Oncol. 2010, 40:717-21. 10.1093/jjco/hyq061

20. Anelli TF, Anelli A, Tran KN, Lebowohl DE, Borgen PI: Tamoxifen administration is associated with a high rate of treatment-limiting symptoms in male breast cancer patients. Cancer. 1994, 74:74-77. 10.1002/1097-0142(19940701)74:1<74::AID-CNCR2820740113>3.0.CO;2-\#

21. Kimmick G: Adjuvant chemotherapy for breast cancer in older women: emerging evidence to aid in decision making. Curr Treat Options Oncol. 2011, 12:286-301. 10.1007/s11864-0110159-Z

22. Zagouri F, Sergentanis TN, Chrysikos D, Zografos E, Rudas M, Steger G, Zografos G, Bartsch R: Fulvestrant and male breast cancer: a case series. Ann Oncol. 2013, 24:265-66. 10.1093/annonc/mds597

23. Macdonal G, Paltiel C, Olivotto IA, Tyldesley S: A comparative analysis of radiotherapy use and patient outcome in male and female with breast cancer. Ann Oncol. 2005, 16:1442-48. 10.1093/annonc/mdi274

24. Foerster R, Foerster FG, Wulff V, Schubotz B, Baaske D, Wolfgarten M, Kuhn WC, Rudlowski C: Matched-pair analysis of patients with female and male breast cancer: a comparative analysis . BMC Cancer. 2011, 11:335. 10.1186/1471-2407-11-335

25. Rushton M, Kwong A, Visram H, Graham N, Petrcich W, Dent S: Treatment outcomes for male breast cancer: a single- centre retrospective case-control study. Curr Oncol. 2014, 21:e400-7. $10.3747 /$ co.21.1730 


\section{Cureus}

26. Cardoso F, Bartlett J, Slaets L, 3. van Deurzen C, van Leewen-Stok E, Porter P, Linderholm B, Hedenfalk I, Schroder C, Martens J, Bayani J, van Asperen C, Murray M, Hudis C, Middleton L, Vermeij J, Peeters S, Fraser J, Nowaczyk M, Rubio I, Aebi S, Kelly C, Ruddy K, Winer E, Nilsson C, Dal Lago L, Korde L, Benstead K, Van Den Weyngaert D, Bogler O, Goulioti T, Dif N, Messina C, Tryfonidis K, Bogaerts J, Giordano S: Abstract S6-05: Characterization of male breast cancer: First results of the EORTC10085/TBCRC/BIG/NABCG International Male BC Program. Cancer Res. 2015, 75:S6-05. Accessed: June 2, 2015:

http://cancerres.aacrjournals.org/content/75/9_Supplement/S6-05. 10.1158/15387445.SABCS14-S6-05 